\title{
Fabricated Diabetes Mellitus: A Rare Presentation of Munchausen Syndrome by Proxy
}

\author{
Priyanka Gupta $^{1} \cdot$ Renjitha Pulikkaparambil $^{1} \cdot$ Vandana Jain $^{2}$ (])
}

Received: 1 July 2021 / Accepted: 6 October 2021 / Published online: 18 October 2021

(c) Dr. K C Chaudhuri Foundation 2021

To the Editor: A 4-y-old girl with polyuria, polydipsia, and weight loss for $2.5 \mathrm{~m}$ was brought to the emergency by her mother, with recent report of blood sugar (BS) of $201 \mathrm{mg} /$ $\mathrm{dL}$ and $\mathrm{HbA} 1 \mathrm{c}$ of $8.7 \%$. The child was fourth-born to a nonconsanguineous Muslim couple, with two elder healthy daughters, death of one newborn son due to pneumonia, and a recent miscarriage. Mother had onset of diabetes during index pregnancy, and was taking oral medicines; paternal grandmother also had diabetes. Child's examination was normal and BS was $110 \mathrm{mg} / \mathrm{dL}$. On OPD follow-up, home BS monitoring ranged from 130 to $210 \mathrm{mg} / \mathrm{dL}$. Initial possibility was type 1 diabetes, but HbA1c (NycoCard ${ }^{\mathrm{TM}}$ Reader II, Abbott Diagnostics, Norway) at our OPD was 4.8\%. On subsequent visit, home BS remained high, another $\mathrm{HbA} 1 \mathrm{c}$ from private lab was $8.0 \%$. However, from our lab, the mother's HbA1c was $5 \%$, discrediting her history of diabetes, and the child's was 5.2\%, leading us to suspect Munchausen syndrome by proxy [factitious disorder imposed on another (FDIOA)]. This was confirmed on hospitalization, as the child remained well, serum C-peptide and insulin were normal. We noted that private lab reports had been neatly altered with black pen. Mother's psychological evaluation suggested presence of stressors (recent miscarriage, her father's death, son's death, not having a male child, and husband staying in a different city). She was counseled over multiple sessions; father was also counseled telephonically, and they were asked to follow-up regularly. Child subsequently remained well with no recurrence of 'symptoms'.

FDIOA is a rare form of child abuse with high morbidity and mortality, in which nonexistent illness is claimed, or

Vandana Jain

drvandanajain@aiims.edu

1 Department of Pediatrics, All India Institute of Medical Sciences, New Delhi, India

2 Division of Pediatric Endocrinology, Department of Pediatrics, All India Institute of Medical Sciences, New Delhi 110029, India symptoms of chronic illness are exaggerated (most often by mother) leading to unnecessary investigations/treatment [1]. Kovacs and Toth had reported a child misdiagnosed as diabetes from 6 to $14 \mathrm{y}$ of age; subjected to multiple hospital visits, blood tests, and dietary restrictions by the father [2]. Our case highlights the importance of early and definitive diagnosis of FDIOA; pediatricians should be alert to recognize the condition, and avoid becoming an inadvertent accomplice of the parents in perpetrating this medical child abuse [3]. Monitoring of the child's safety is essential; filing of medicolegal case, and involving local child welfare committees should be considered.

Data Availability Yes.

\section{Declarations}

Consent for Publication Obtained.

Conflict of Interest None.

\section{References}

1. Kucuker H, Demir T, Oral R. Pediatric condition falsification (Munchausen syndrome by proxy) as a continuum of maternal factitious disorder (Munchausen syndrome). Pediatr Diabetes. 2010;11:572-8.

2. Kovacs CS, Toth EL. Factitious diabetes mellitus and spontaneous hypoglycemia. Consequences of unrecognized munchausen syndrome by proxy. Diabetes Care. 1993;16:1294-7.

3. Bass C, Glaser D. Early recognition and management of fabricated or induced illness in children. Lancet. 2014;383:1412-21.

Publisher's Note Springer Nature remains neutral with regard to jurisdictional claims in published maps and institutional affiliations. 